http://jmscr.igmpublication.org/home/ ISSN (e)-2347-176x ISSN (p) 2455-0450 crossref DOI: https://dx.doi.org/10.18535/jmscr/v7i8.135

$\underline{\text { Research Article }}$

\title{
Anti-convulsant activity of Kushmandagira swarasa (juice of seed containing part of Benincasa hispida (Thunb.)Cogn.) bhavitha Yashtimadhu choorna (Glycyrrhiza glabra Linn.) in Wistar Albino rats
}

\author{
Authors
}

\section{Niya T Sivan ${ }^{1}$, Dr Sara Monsy Oommen²}

${ }^{1}$ PG Scholar, Department of Dravyagunavijnanam, Govt. Ayurveda College, Tripunithura
${ }^{2}$ Professor, Department of Dravyagunavijnanam, Govt. Ayurveda College, Thiruvanthapuram

\begin{abstract}
Epilepsy is a group of neurological disease, characterized by epileptic seizures. On analysing the symptoms, epilepsy can be correlated with Apasmara mentioned in Ayurveda. Kushmandagira swarasa (juice of seed containing part of Benincasa hispida (Thunb.)Cogn.) bhavitha Yashtimadhu choorna (Glycyrrhiza glabra Linn.) is mentioned in the context of Apasmara chikitsa in an Ayurvedic classic, Yogaratnakaram. So the present study was done the evaluation of the anti-convulsant activity of Kushmandagira swarasa bhavitha Yashtimadhu choorna in Wistar Albino rats using MES (Maximal Electro-Shock Seizure) model. Test drug was given in three doses (calculated effective dose, half the calculated effective dose and double the calculated effective dose) for seven days continuously in the suspension form. The assessment was done on the 8th day. Hind limb extension time in seconds is considered as the assessment criteria and the value obtained were compared with that of control group. The anti convulsant activity was proved in all the three test groups and the results were analysed using Mann- Whitney test and Kruskal-Wallis test. The study showed statistically significant results in all the test groups. Thus it confirms the anti convulsant activity of Kushmandagira swarasa bhavitha Yashtimadhu choorna.

Keywords: Kushmandagira swarasa, Yashtimadhu choorna, Anti convulsant activity.
\end{abstract}

\section{Introduction}

Apasmara is a disease which affects the smrithi (memory), budhi (intelligence) and satwa (behaviour) of a person. The prime feature of apasmara is bheebatsa cheshtta (convulsions). By analysing the symptoms, Apasmara can be co related with Epilepsy. Epilepsy is a group of neurological diseases characterised by epileptic seizures. These are the result of excessive and abnormal neuronal activity in the brain cortex. Epilepsy certainly affects one's personal and social life.
Kushmandagira swarasa (juice of seed containing part of Benincasa hispida (Thunb.)Cogn.) bhavitha Yashtimadhu choorna (Glycyrrhiza glabra Linn.) is explained by an Ayurvedic classic Yogaratnakaram in the apasmara chikitsa as course of three days medication. Yashtimadhu, Glycyrrhiza glabra Linn is considered as one among the medhya dravya by Acharya Charaka. Kushmanda (Benincasa hispida (Thunb.)Cogn.) is recognised as a drug which has the property to destroy the vikara (diseases) of chethas (mind). Till now, no scientific validation is done on the combination of these two drugs on anti 
convulsant activity. So a reverse pharmacological study has been undertaken to provide an experimental validation for same.

\section{Materials and Methods}

\section{Materials used}

Wistar Albino rats of each sex weighing 150 to 200gm, Test drug (Kushmandagira swarasa (juice of seed containing part of Benincasa hispida (Thunb.)Cogn.) bhavitha Yashtimadhu choorna (Glycyrrhiza glabra Linn.), Electro-convulso-meter with ear electrodes, Stop watch, Cotton, Xylocaine gel, Distilled water, Feeding cannula, Gloves, Weighing machine.

\section{Preparation of the Test Drug}

Dried roots of Yashtimadhu (Glycyrrhiza glabra Linn.) were powdered and sieved properly using 120 mesh size. Kushmandagira (Seed containing part of Benincasa hispida (Thunb.)Cogn) was crushed and juice was extracted using a mixer without adding water. After that suffient amount of Yashtimadhu Choorna (Glycyrrhiza glabra Linn.) was taken and did bhavana (trituration) with adequate amount of swarasa of Kushmandagira (seed containing part of Benincasa hispida (Thunb.)Cogn.). The trituration was done continuously for three hours and the entire process was repeated for seven times. After the trituration, the powder was again dried, powdered and sieved properly. The prepared drug was preserved in an air tight container.

\section{Dose of the Test Drug}

Dose of Yashtimadhu in the API Vol 1 is taken as the dose of test drug since it is the main ingredient. In API, Dose is documented in between 2 to $4 \mathrm{gm}$ per day. Test drug is prepared after seven consecutive bhavana. So that the dose can be reduced in the concept that bhavana will increase the potency of the drug. In the present study, dose of test drug in human being is taken as $2 \mathrm{gm}$. As per the Paget and Barnes table, animal dose is calculated using the rat conversion factor.

Animal dose $=$ Human dose $\times 0.018$ for 200 gm of animal.

$$
=2 \mathrm{~g} \times 0.018=0.04 \mathrm{~g} / 200 \mathrm{gm} \text { of animal. }
$$

For the anti- convulsant study, doses are taken as $1 / 2$ $\mathrm{X}, \mathrm{X}, 2 \mathrm{X}$ where $\mathrm{X}$ represents the effective test dose.

\section{Procedure}

The test drug was administered continuously for seven days and the assessment was done on 8th day. Each day, after giving the test drug, animal was restricted from food for first 2 hours. There was no restriction for the water supply during this period. On 8th day, each one of the groups was studied. The animal was restrained by hand and subjected to electric shock (150 mA for 0.2 seconds) through Trans auricular electrodes (ECT- Electro convulsant unit). The rat was released immediately following the electrical stimulation to permit maximal seizures. Phases of convulsion were recorded with a stop watch in each rat for first two minutes. After that, animal was kept under the observation till the recovery period (normally 3 hours).

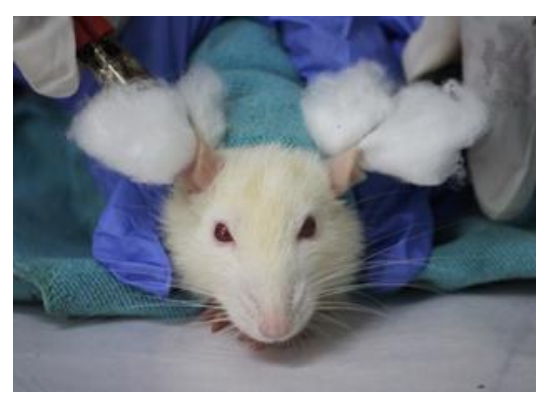

Figure 1 Wistar Albino rat with trans-auricular electrodes

The maximal seizure typically consists of a short period of initial tonic flexion of hind limb and prolonged period of tonic extension followed by clonic convulsion, stupor and recovery. Reduction of duration of Tonic Hind Limb Extension time (THLE) in seconds was taken as the assessment criteria. The Tonic Hind Limb Extension time of test groups was compared to that of control group. 


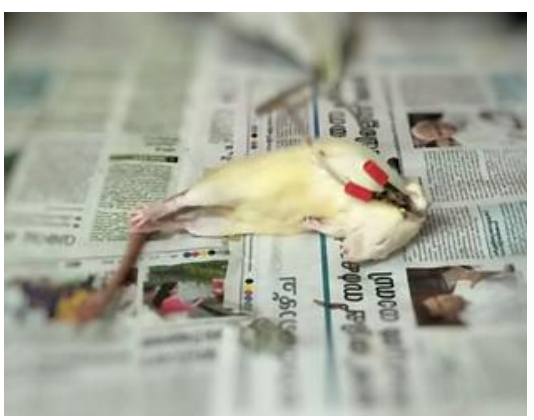

Figure 2 Wistar Albino rat during hind limb extension

Table 1: Groupings of Animals

\begin{tabular}{|c|c|}
\hline Group & Dose \\
\hline Group A & Standard diet \\
\hline Test Group 1 & $0.02 \mathrm{gm} / 200 \mathrm{gm}$ body weight \\
\hline Test Group 2 & $0.04 \mathrm{gm} / 200$ gm body weight \\
\hline Test Group 3 & $0.08 \mathrm{gm} / 200$ gm body weight \\
\hline
\end{tabular}

\section{Result}

Table 2 Hind Limb Extension time of different groups

\begin{tabular}{|c|c|}
\hline Group & Mean \\
\hline Group A & 16.67 \\
\hline TG1-1/2X & 8.833 \\
\hline TG2-X & 7.667 \\
\hline TG3-2X & 4.000 \\
\hline
\end{tabular}

Values are expressed as mean, $n=6$

Graph 1. Comparison of Hind Limb Extension Time between Groups

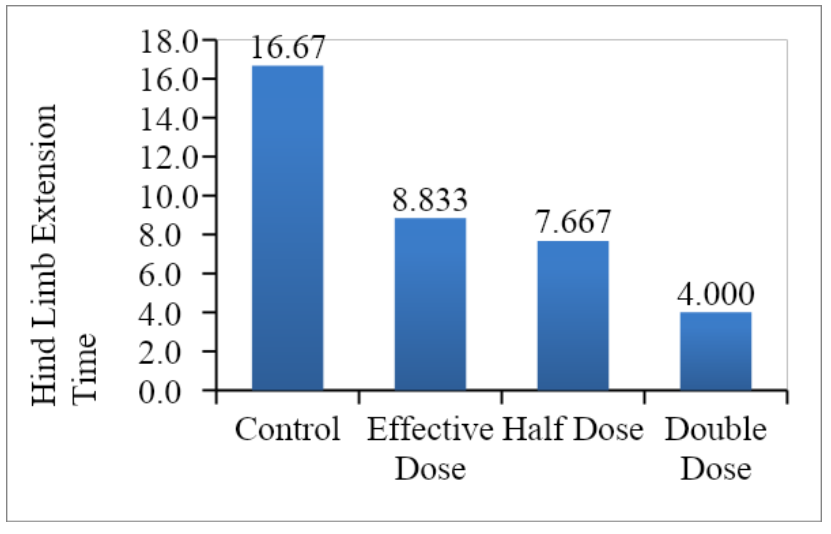

\section{Analysis and interpretation of data}

Table 3 Table showing the statistical difference between the groups.

\begin{tabular}{|l|c|c|c|c|}
\hline Group & Mean & SEM & Rank & p-Value \\
\cline { 1 - 4 } Group A & 16.67 & 0.558 & 21.33 & \multirow{2}{*}{0.002} \\
\cline { 1 - 4 } TG1:1/2X & 7.667 & 2.565 & 11.3 & \\
\cline { 1 - 4 } TG2-X & 8.833 & 0.401 & 11.00 & \\
\hline TG3-2X & 4.000 & 1.862 & 6.333 & \\
\hline
\end{tabular}

Here the p-value is less than the significance level 0.05 ; the difference in hind limb extension time between groups is significant. That is, there is a significant difference in hind limb extension time between groups. The table reveals that the hind limb extension time is significantly lower in effective dose $(8.833 \pm 0.401)$, half dose $(7.667 \pm 5.565)$ and double dose $(4.000 \pm 1.862)$ compared to control $(16.67 \pm 0.558)$. The mean rank also confirms that hind limb extension time is lower in effective dose (11.00), half dose (11.33) and double dose (6.333) compared to control (21.33).

\section{Discussion}

Complete abolition or reduction of tonic hind limb extension time in seconds was the assessment criteria. Tonic hind limb extension was reduced in the test drug treated groups compared to control group. Both the drugs in the formulation are having action on preventing the seizures on the basis of phytochemicals present in it. Glycyrrhiza glabra Linn is having glycyrrhizin as the main chemical constituent. It is the derivative of glycyrrhinic acid. It has the capacity to alter the activity of ion transport processes including ion channels and inhibition of $\mathrm{Na}^{+}-\mathrm{K}^{+}$-ATPase. ${ }^{[1]}$ This will block the voltage gated $\mathrm{Na}+$ channels that remain open due to repetitive neuronal firing and prolong the duration of inactivated phase of the neurons and delay its reversion to the resting phase. The seeds of Benincasa hispida (Thunb.)Cogn contains GABA abundantly. ${ }^{[2]}$ GABA is the inhibitory neurotransmitter in the central nervous system. Trituration with the juice of seed containing part of the Benincasa hispida (Thunb.)Cogn may increase the GABAergic content in the combination. So through this synergistic action of both the drugs, seizure can be controlled and prevent the further attacks. It may increase the ability of neuronal structures to withstand the seizure assault. It will improve the overall physical and mental development of the affected and will prevent from further seizure attacks. 


\section{Conclusion}

The results confirm that Kushmandagira swarasa (juice of seed containing part of Benincasa hispida (Thunb.)Cogn) bhavitha Yashtimadhu choorna (Glycyrrhiza glabra Linn.) possess anti convulsant activity.

\section{Acknowledgement}

I express heartfelt gratitude to my Guide Dr. Sara Monsy Oommen MD (Ay), Professor, Dr. P.Y. Ansary, M D (Ayu.), Professor \& HOD, and to Dr. Shincymol VV, Associate Professor, Department of Dravyagunavijnanam, Govt. Ayurveda College, Tripunithura, for valuable guidance rendered throughout the study.

\section{References}

1. M.Nassiri-Asl et al. Anticonvulsant effects of Aqueous extract of Glycyrrhiza glabra Root in PTZ-induced seizure in Mice, IJP, 2007, Vol 3, Issue 5, p.no: 432-434.

2. The Wealth of India, Raw materials, A Dictionary of Indian Raw Materials \& Industrial Products, Vol.-2:B, Publications \& Information Directorate, Council of Scientific of Scientific \& Industrial Research, New Delhi p.no : 453. 